\title{
LA EXTRATERRITORIALIDAD DE LA LEY PENAL: EL PRINCIPIO DE JUSTICIA UNIVERSAL, SU APLICACIÓN EN COLOMBIA
}

Henry Torres Vásquez*

Fecha de recibido: 13 de agosto de 2012

Fecha de aprobado: 2 de abril de 2013

Artículo de reflexión

Forma de citación: Torres, H. (2013). La extraterritorialidad de la ley penal: el principio de la justicia universal, su aplicación universal en Colombia. Revista Prolegómenos. Derechos y Valores, 16, 31, 99-115.

\section{Resumen}

En la actualidad en los crímenes considerados de Lesa humanidad, entre otros, se aplica el principio de jurisdicción o de justicia penal universal; de ese modo eventualmente, esta clase de delitos, pueden ser investigados y juzgados en aplicación del Estatuto de la Corte Penal Internacional, o bien en ejercicio de ese mismo principio pero ejercido por cualquier país. Estados como España, Reino Unido, Bélgica, etc., vienen aplicando la jurisdicción universal en mediáticos casos de ex militares argentinos o en el sonado caso de Augusto Pinochet.

En este trabajo se hace un análisis de las infracciones que logran transgredir normas consideradas protectoras de bienes jurídicos universales. Nuestro objetivo principal radica en explicar este principio en aras de evitar la impunidad en delitos de naturaleza internacional. Por tal razón, se matiza en el Principio de Jurisdicción Universal aplicado en España, en esa perspectiva se analizan recientes crímenes de Lesa humanidad sucedidos en Colombia que se subsumen en la categoría de delitos que podrían ser llevados a la jurisdicción universal; en ese sentido, se estudian las características de la extraterritorialidad de la ley penal colombiana en el plano internacional.

\section{Palabras clave}

Justicia Universal, Extraterritorialidad de la Ley Penal, Lesa Humanidad, Derecho Internacional Humanitario, Corte Penal Internacional.

* Artículo que corresponde a los avances de la investigación: "Persecución al delito de terrorismo en la ciudad de Bogotá", financiada por la Universidad Libre, que pertenece al Grupo que el autor dirige: "Derecho penal, derechos humanos y derecho disciplinario", categoría C Colciencias.

Abogado de la Universidad Nacional de Colombia, Doctor en Empresa y Sistema Penal, de la Universidad Jaime I de Castellón, España. Profesor titular e investigador de jornada completa de la Universidad Libre de Bogotá D.C. Docente de los postgrados en derecho penal de las universidades Santo Tomás, Autónoma de Colombia, Libre y Gran Colombia. Correo electrónico: henry.torresv@unilibrebog.edu.co 


\title{
EXTRATERRITORIALITY OF CRIMINAL LAW: THE PRINCIPLE OF UNIVERSAL JUSTICE, ITS APPLICATION IN COLOMBIA
}

\begin{abstract}
Currently considered the crimes against humanity, among others, applying the principle of criminal justice jurisdiction or universal, thereby eventually this kind of crime can be investigated and tried under the Statute of the International Criminal Court or in the exercise of that same principle exercised by any country. Countries like Spain, UK, Belgium, etc.., have applied universal jurisdiction in media cases of former Argentine military or the famous case of Augusto Pinochet.

This paper makes a brief analysis of the offenses that achieve standards that are protective of transgressing universal legal goods. Our primary goal is to explain this principle in order to avoid impunity in crimes of international nature. For this reason it is clarified in the Principle of Universal Jurisdiction applied in Spain, in that perspective we analyze recent crimes against humanity that occurred in Colombia that are subsumed under the category of crimes that could be brought to universal jurisdiction in that sense are studied the characteristics of the extraterritoriality of Colombian criminal law at the international level.
\end{abstract}

\section{Keywords}

Universal Justice, Extraterritoriality of the Penal Law, Crimes Against Humanity, International Humanitarian Law, International Criminal Court.

\section{A EXTRATERRITORIALIDADE DA LEI PENAL: O PRINCÍPIO DA JUSTIÇA UNIVERSAL, E A SUA APLICAÇÃO NA COLÔMBIA}

\section{Resumo}

Atualmente, nos crimes contra a humanidade, entre outros, se aplica o princípio da jurisdição ou de justiça penal universal, assim, eventualmente, esse tipo de crime, podem ser investigados e julgados nos termos do Estatuto do Tribunal Penal Internacional, ou no exercício deste mesmo princípio exercido por qualquer país. Estados como a Espanha, Reino Unido, Bélgica, etc., já têm aplicado jurisdição universal em casos mediáticos como ex-militares argentinos ou o famoso caso de Augusto Pinochet.

Neste artigo se faz uma breve análise dos crimes que fazem violar as regras consideradas de proteção aos bens jurídicos universais. Nosso principal objetivo é explicar este princípio a fim de evitar a impunidade nos crimes de natureza internacional. Por esta razão, se considera o principio de Jurisdição Universal aplicado na Espanha, nessa perspectiva analisam-se recentes crimes contra humanidade que ocorreram na Colômbia que estão subsumidos na categoria de crimes que poderiam ser trazidas à jurisdição universal, nesse sentido, estudamse as características da extraterritorialidade da lei penal colombiana a nível internacional.

\section{Palavras-chave}

Justiça Universal, extraterritorialidade da Lei Penal, Crimes contra a Humanidade, Direito Internacional Humanitário, Tribunal Penal Internacional. 


\section{INTRODUCCIÓN}

El Principio de Justicia Universal, de Jurisdicción Universal o de Justicia Mundial permite la aplicación de justicia en el orden internacional. Así pues, un Estado puede conocer de un crimen, puede juzgar y ejecutar lo juzgado, siempre que quien cometa un crimen determinado como grave, que tenga que ver con bienes jurídicos necesarios de protección en el ámbito universal y en el Estado en donde se perpetraron los crímenes, o en su país de origen no sea procesado, o no se asuma el caso, o no puedan ser juzgados o no se pueda ejecutar la condena ya sea porque el Estado no quiere o no puede investigar, juzgar y condenar, o bien cuando se hace una burla de justicia; en esos eventos cualquier país del mundo puede hacer justicia, siempre que lo haga bajo los postulados de la buena fe, la cual se encuentra determinada en el principio 1.5 de los denominados Principios de Princeton: "El Estado ejercerá la jurisdicción universal de buena fe y de conformidad con sus derechos y obligaciones de derecho internacional".

De acuerdo con los principios de Princeton "se entiende por jurisdicción universal una jurisdicción penal sustentada exclusivamente en la naturaleza del delito, con prescindencia del lugar en que éste se haya cometido, la nacionalidad del autor presunto o condenado, la nacionalidad de la víctima o todo otro nexo con el Estado que ejerza esa jurisdicción". En nuestra opinión es más ajustado hablar de justicia universal, por lo tanto lo señalaremos como el principio de justicia universal (en adelante PJU) en razón a que el principio no alude sólo a cuestiones de tipo jurisdiccional, sino también de tipo sustantivo.

El país en donde se ha aplicado en diferentes ocasiones es España, allí se materializa en el ordenamiento jurídico, a través del artículo 23.4 de la Ley Orgánica del Poder Judicial; en ese artículo se establece la competencia de la jurisdicción española para juzgar los delitos de genocidio, lesa humanidad y terrorismo, cometidos en el extranjero aunque sean realizados por personas de otra nacionalidad.

De conformidad con el Código Penal colombiano, existen tres posibilidades de aplicación de justicia; la establecida en el artículo 14 sobre territorialidad absoluta, el artículo 15 sobre territorialidad por extensión y la contenida en el artículo 16 sobre la extraterritorialidad de la ley penal colombiana. En la medida en que a través de ese artículo se pueden castigar conductas cometidas para infracciones que transgreden normas consideradas protectoras de bienes jurídicos universales.

Así pues, en el mencionado artículo 16 se plasma el Principio de Jurisdicción Universal, principio que ha sido aplicado en Europa, especialmente en España. A través de él se pueden iniciar acciones penales para una gran diversidad de conductas, en consecuencia en este artículo nos preguntamos ¿qué características tiene la extraterritorialidad de la ley penal colombiana, específicamente el Principio de Justicia Universal en Colombia?

En esa medida nuestro gran objetivo es explicar el principio, con el fin de crear conciencia sobre la posibilidad real de evitar la impunidad en crímenes que atentan contra la humanidad entera.

Partamos de especificar que el PJU es para la comunidad internacional un principio de jurisdicción universal o extraterritorialidad a través del cual los Estados parte de innumerables Convenios y tratados internacionales están dispuestos a castigar a los autores y cómplices de delitos considerados graves por la comunidad internacional. Los Estados parte pueden aplicar el principio de justicia universal sin tener en consideración las fronteras, el sitio de ocurrencia de la conducta punible, sin tener en cuenta el lugar donde se violo el bien jurídico y sin importar la nacionalidad de los sujetos activos o pasivos.

Varios instrumentos internacionales son bastante importantes en la construcción, consoli- 
dación y puesta en marcha del PJU: la llamada Cláusula Martens que fuera diseñada por el ruso de Martens. Esta cláusula se encuentra en el Preámbulo del Convenio sobre las leyes y costumbres de la guerra terrestre adoptado en La Haya el 18 de octubre de 1907. Junto a ella se encuentran los principios de Princeton.

Además se encuentra el Estatuto de Roma de la Corte Penal Internacional y resoluciones de la ONU entre las que se destaca la Resolución 3074 (XXVIII) de la Asamblea General, del 3 de diciembre de 1973.

Si tenemos en cuenta los principios de Princeton, encontramos argumentos loables en torno a la necesidad de realizar ajustes al PJU. En el año 2001, un conjunto de expertos produjo el texto definitivo conocido hoy como los principios de Princeton, allí se constituyeron algunas directrices para lograr hacer efectivo el PJU. En él se incorporaron unos principios aplicables que eran y son necesarios en palabras de los redactores de los principios de Princeton es necesario "elucidar y ordenar una esfera del derecho penal internacional que adquiere cada vez más importancia: la del enjuiciamiento en tribunales nacionales de delitos graves de derecho internacional, con arreglo a la jurisdicción universal y cuando no existan nexos jurisdiccionales tradicionales con las víctimas o los perpetradores de los crímenes". La preocupación del grupo era lo dispersa, difusa "heterogénea, incoherente y mal entendida", por lo tanto si "mientras impere esa situación, este instrumento de lucha contra la impunidad bien puede verse acosado por la incoherencia, la confusión y, a veces, una justicia desigual". Todo esto redunda en que" si bien la jurisdicción universal plasma la promesa de una mayor justicia", su jurisprudencia parece indicar que no hay un grado razonable de justicia.

De acuerdo con el Código Penal colombiano existe tres posibilidades de aplicación de justicia, el del artículo 14 sobre territorialidad absoluta, el del artículo 15 sobre territorialidad por extensión y el del artículo 16 sobre la extrate- rritorialidad de la ley penal colombiana. En la medida en que a través de ese artículo se pueden castigar conductas cometidas para infracciones que transgreden normas consideradas protectoras de bienes jurídicos universales.

Así pues, en el mencionado artículo 16 se plasma el Principio de Jurisdicción Universal, principio que ha sido aplicado en Europa, especialmente en España. A través de él se pueden iniciar acciones penales para una gran diversidad de conductas, en consecuencia en el presente trabajo nos preguntamos ¿Qué características tiene el Principio de Justicia Universal en Colombia?

Como estrategia metodológica se plantea que este artículo es resultado de una investigación básicamente jurídica, en la que se ha contado con el apoyo axial del método comparativo para poder explicar las características del Principio de Justicia Universal. Ante el numeroso material bibliográfico consultado, el método analítico deductivo permitió analizar con rigor y profundidad el problema de los delitos cometidos en Colombia que son de competencia universal tales como el terrorismo, lesa humanidad, genocidio crímenes de guerra y de agresión y su relación el principio de Justicia o de Jurisdicción Universal. De ese modo se logró entender mejor el problema objeto de investigación y se pudo obtener una respuesta más acorde con la doctrina internacional.

\section{LA EXTRATERRITORIALIDAD DE LA LEY PENAL: EL PJU, SU APLICACIÓN EN COLOMBIA}

Ante un horizonte de impunidad en países en vías de desarrollo desde hace unos años, el derecho penal ha abierto un camino: esto es la posibilidad de brindar justicia de forma extraterritorial. Este importante paso, junto a un mayor conocimiento y apropiación de los derechos humanos y del Derecho Internacional Humanitario en medio de un mundo globalizado, permite evitar que algunos de los delitos 
en los que se atente contra bienes jurídicos de naturaleza supra estatal queden en la impunidad. Hasta hace algunos años los victimarios de esa categoría de delitos, permanecían muy tranquilos, dada su condición detentadores de poder.

Hoy a pesar de esa situación, tienen tantos miedos, como intereses económicos en juego y aún así ostentando la categoría de provocadores, instigadores o ejecutores de los delitos que atentan contra toda la humanidad, ya no les queda tan fácil conseguir que sus crímenes queden en la impunidad, lo cual conlleva a la corrupción y a toda suerte de violaciones a un sinnúmero de derechos, incluidos los Derechos Humanos; es sabido que la impunidad genera descontento, incredulidad en la administración y sistema de justicia; la impunidad es entendida como la ausencia de castigo del crimen cometido, lo que preocupa es la permanencia de la estructura institucional que permite, la continuidad de criminales y crímenes de tal calado.

Precisamente el PJU como forma actual de aplicación del derecho internacional es un instrumento para el respeto por los Derechos Humanos, es teóricamente la posibilidad real de alcanzar niveles mínimos de justicia. El principio de la jurisdicción universal defiende las normas que hacen parte del derecho internacional humanitario, en Colombia el Código Penal señala en su artículo 2 que: "Las normas y postulados que sobre derechos humanos se encuentren consignados en la Constitución Política, en los tratados y convenios internacionales ratificados por Colombia, harán parte integral de este código", también hace parte del llamado bloque de constitucionalidad.

\section{EL SUSTENTO LEGAL DEL PJU EN COLOMBIA}

El PJU está amparado legalmente en Colombia por dos razones: en primer lugar, porque su aplicación se hace imperativa en la medida en que Tratados y Convenios Internacionales, son de aplicación por vía del llamado bloque de constitucionalidad, $y$, en segundo lugar, porque del artículo 16 del Código Penal, (numeral 6) de manera taxativa consagra su aplicación en el ámbito interno, siempre que se den las condiciones allí señaladas, este artículo señala que:

Extraterritorialidad.

La ley penal colombiana se aplicará:

6. Al extranjero que haya cometido en el exterior un delito en perjuicio de extranjero, siempre que se reúnan estas condiciones:

a) Que se halle en territorio colombiano;

b) Que el delito tenga señalada en Colombia pena privativa de la libertad cuyo mínimo no sea inferior a tres (3) años;

c) Que no se trate de delito político, y

d) Que solicitada la extradición no hubiere sido concedida por el gobierno colombiano. Cuando la extradición no fuere aceptada habrá lugar a proceso penal.

En el caso a que se refiere el presente numeral no se procederá sino mediante querella o petición del Procurador General de la Nación y siempre que no hubiere sido juzgado en el exterior.

Recordemos que en nuestro país se han venido implementando en la Constitución los tratados o Convenios internacionales que se refieren a delitos de trascendencia trasnacional como son el genocidio, lesa humanidad, crímenes de guerra y crímenes de agresión. Ya que se considera que determinados valores universales deben ser amparados. Por tal razón, el Estado colombiano reconoce la jurisdicción de la Corte Penal Internacional (Sentencia C-574-92).

En realidad la Corte Constitucional contempla que el inciso segundo del artículo 93 de la Constitución se refiere a la prevalencia de los tratados o convenios internacionales en el orden jurídico interno, siempre y cuando dichas normas hubiesen sido integradas en la normatividad colombiana a través de la ratificación 
del Estado, previo análisis de la constitucionalidad.

Los requisitos para ser incorporados a nuestra Carta Política son fundamentalmente dos; por un lado, que se trate del reconocimiento de un derecho humano; y por otro lado que se trate de un derecho cuya limitación se prohíba durante los estados de excepción (artículo 214 y s.s de la Constitución colombiana).

En otras ocasiones en los altos tribunales colombianos se ha debatido el tema de la jurisdicción universal, así por ejemplo, sobre la particular definición de qué es la jurisdicción universal, la Corte Constitucional ha señalado lo siguiente (Corte Constitucional Sentencia C-1189 de 2000):

d) El principio de jurisdicción universal, que atribuye a todos los Estados del mundo la facultad de asumir competencia sobre quienes cometan ciertos delitos que han sido especialmente condenados por la comunidad internacional, tales como el genocidio, la tortura o el terrorismo, siempre que tales personas se encuentren en su territorio nacional, aunque el hecho no haya sido cometido allí. Este principio, cuyo carácter consuetudinario no ha recibido general aceptación, ha sido, no obstante, consagrado expresamente en varios convenios internacionales que vinculan a Colombia, como las Convenciones contra la Tortura, contra el Genocidio, contra el Apartheid y contra el Tráfico Ilícito de Estupefacientes; por ello, puede afirmarse que, en este punto del desarrollo del derecho internacional, el principio de jurisdicción universal opera cuando consta en un tratado.

En torno a que es para Colombia el mencionado principio esta misma Corte dijo:

(...) se trata, en esencia, de un mecanismo de cooperación internacional en la lucha contra ciertas actividades repudiadas por la sociedad de naciones que, en esta medida, coexiste con las competencias jurisdiccionales ordinarias de los Estados, sin imponerse sobre ellas; así se dice expresamente en los múltiples tratados en los cuales se consagra.

En otra sentencia, la Corte Suprema de Justicia en el año 2001 manifestó:

(...) el principio de jurisdicción universal que, como ya se vio, coexiste con las competencias jurisdiccionales ordinarias de los Estados en materia criminal, tal y como lo dispone el artículo 4, numeral 3, en cuestión. Esto quiere decir que, junto con las competencias jurisdiccionales que les asisten por virtud de los principios de territorialidad y nacionalidad, los Estados pueden aplicar sus leyes penales, únicamente sobre la base de que los delincuentes en cuestión se encuentren en su territorio; pero ello no obsta para que el Estado nacional de tales personas, o el Estado en cuyo territorio se cometió el delito, ejerzan su propia jurisdicción, si en cada caso concreta las circunstancias tornan tal ejercicio razonable y prevalente (Proceso $\mathrm{N}^{\circ}$ 16724, 2/08/2.001).

En Sentencia C-979 de 2005 expresó:

Para la Corte, la impunidad frente a las violaciones de derechos humanos y derecho internacional humanitario es mucho más grave e inaceptable, que los agravios inferidos mediante otras formas de criminalidad, no solamente por la intensidad de la afectación de la dignidad humana que dichos comportamientos implican, sino además porque la comunidad internacional, en virtud del principio de complementariedad, está comprometida en la sanción de esas conductas.

Como se puede colegir, aquí ha manifestado su preocupación por violaciones a los derechos humanos y al derecho internacional hu- 
manitario debido a que afectan a Colombia y a la comunidad internacional, y la persecución a esos criminales se tiene que hacer por mandato internacional, luego esas conductas no pueden quedar impunes.

Las mismas consideraciones de la Corte Constitucional en la mencionada Sentencia (C1189 de 2000) han sido traídas a colación en Sentencia de la Corte Suprema de Justicia № 27650 del 28 de noviembre de 2007.

Como se observa, la aplicación del PJU ha sido reconocida y aceptada, ciertamente, tanto la Constitución y los gobiernos como el sistema jurídico colombiano de forma voluntaria han cedido el ejercicio de su soberanía a cualquier país que pueda o desee aplicar el principio, basados en la necesidad de impedir la impunidad de ciertos crímenes muy graves en los que se deja que una institución supra-nacional juzgue sus nacionales.

De ningún modo el Estado deja de ser el principal garante del contrato social contraído con sus ciudadanos cuando deja que se aplique el PJU, los derechos de ningún ciudadano se ven vulnerados; al contrario, los derechos de algunos criminales ejecutores de crímenes considerados graves se ven minimizados en aras de proteger la colectividad. De la misma manera, el principio de soberanía nacional tampoco se resquebraja, sigue predominando ya que el PJU es de aplicación muy especial y para cierto tipo de crímenes en determinados casos.

Del PJU proviene la aplicación en Colombia de la jurisdicción de la CPI, luego el Estatuto de Roma hace parte sustancial del derecho penal colombiano establecido en compromisos adquiridos en los tratados o Convenios ratificados por Colombia, también estos se refieren a la competencia para investigar, juzgar y, eventualmente, condenar a presuntos responsables penales de estos delitos.

Es así como el Estatuto de la Corte Penal Internacional de 1998 es de aplicación para casos sucedidos en Colombia en los que la conducta punible se puede subsumir como uno de los cuatro delitos de los cuales tiene competencia la CPI, de acuerdo al artículo 5 del Estatuto de Roma. Los crímenes de la competencia de la Corte, a saber son: a) El crimen de genocidio; b) Los crímenes de lesa humanidad; c) Los crímenes de guerra; d) El crimen de agresión. En otros términos, esta Corte no es competente para juzgar otros delitos acaecidos en Colombia, crímenes como las masacres que en inusitado número han sido o son objeto de investigación, o, en el peor de los casos, no han sido investigadas, en absoluto podrán ser investigadas por la CPI.

Los demás delitos en los que la sociedad ha demandado justicia, como el acceso carnal violento en menores de edad, homicidios, o, inclusive, un delito de peligro como el terrorismo, no es de competencia de la CPI, tampoco lo es el denominado terrorismo que proviene del Estado (Torres, 2010, p. 142). Cabe llamar la atención respecto a los taxativos requisitos exigidos por el principio de legalidad que impiden que la competencia de la Corte pueda ser extendida.

Pero no es el único problema de aplicación de justicia que tiene la Corte, para nuestro país. El hecho de que solo sea aplicable justicia para hechos sucedidos en Colombia después del 1 de julio de 2002 hace mucho más difícil la solución, al menos parcial, de la impunidad. En otras palabras, la Corte no actúa retroactivamente, aunque en el caso de delitos de ejecución permanente como la desaparición forzada, por ejemplo, si que tiene competencia siempre que la desaparición forzada sea catalogada como un delito de lesa humanidad. Recuérdese que son delitos de lesa humanidad los que tienen la especial característica de ser generalizados o sistemáticos, luego son crímenes de lesa humanidad ciertas conductas violentas, enunciadas por el artículo 7 del Estatuto de la Corte Penal Internacional, cuando se cometen "como parte de un ataque generalizado o sistemático contra una población civil y con cono- 
cimiento de dicho ataque". De la generalidad, es importante señalar que es la masividad que se dice existe cuando las conductas punibles causan un número significativo de víctimas. De otra parte, la sistematicidad, hace referencia a lo metódico, así pues cuando las conductas punibles han sido ideadas, planeadas y organizadas.

Finalmente, una de las críticas más severas respecto a la CPI. parte de lo selectiva que hasta ahora ha sido. Se señala con mucho acierto que la Corte solo se dedica a hacer justicia en África; Forer dice que la CPI. no se ha preocupado en casos como los sucedidos en Colombia y estos son relegados; siendo una "muestra no sólo de un tácito interés en este territorio, sino también de una especie de neocolonialismo por parte de la Fiscalía del tribunal internacional hacia el continente africano; influenciada principalmente por países del denominado primer mundo" (Forer, 2010). Es primordial señalar que la CPI. no es competente para investigar y juzgar crímenes como el terrorismo. A pesar de esto, en nuestra opinión si será competente respecto al terrorismo de Estado, siempre que este sea interpretado como un delito de lesa humanidad. En consecuencia es obligado entrar a analizar esta situación en el apartado que sigue.

\section{PROBLEMAS DE APLICACIÓN DE LA CPI. EN COLOMBIA}

En primer lugar hay que manifestar que la CPI. es una Corte permanente que investiga y lleva ante la justicia a los individuos, no a los Estados. En esa medida la CPI. establece la responsabilidad penal individual tanto de aquellos violadores de los derechos humanos como de violadores del derecho internacional humanitario y, tal como decíamos más arriba, los delitos sometidos a su jurisdicción son el genocidio, los crímenes de guerra, los crímenes de agresión y los crímenes de lesa humanidad que, por supuesto, son atentatorios de los derechos humanos. Igualmente, es obligado se- ñalar que la CPI. tiene un carácter subsidiario frente a la justicia colombiana, lo que significa que en ningún caso sustituye la justicia colombiana, aunque es cierto que en caso de no poder o no querer hacer justicia, o en el evento de hacer una parodia de justicia, la Corte será competente para investigar, juzgar y condenar esas conductas punibles.

Aún así los críticos entienden que para la aplicación de la jurisdicción universal, en el caso específico de la Audiencia nacional española, se apela al carácter internacional de los hechos, "a pesar de que la misma ni viene recogida expresamente en la Ley Orgánica del Poder Judicial ni viene impuesta por ningún tratado internacional" (Gil, 2005, p. 1). Esto obligaría a reconsiderar los requisitos exigidos para su aplicabilidad, los que parecen van a encaminarse a la necesidad de que haya víctimas españolas, en los casos a investigar.

De manera general, ya se ha ido avanzando en materia de los requisitos para ejercer la jurisdicción universal por parte de un Estado; Cassese recuerda que los jueces Guillaume, Rezek y Ranjeva han manifestado que quien cometa crímenes puede ser juzgado por un Estado con un proceder legítimo, siempre que se cumplan las siguientes condiciones:

a) "Que el Estado, antes de iniciar las diligencias brinde al Estado nacional la posibilidad de pronunciarse sobre los cargos contra la persona;

b) Que el fiscal o el juez de instrucción sean independientes del gobierno;

c) Que la acción penal se inicie a solicitud de las víctimas o sus parientes;

d) Que se trate de crímenes considerados como graves y odiosos por toda la comunidad internacional; y que el ejercicio de la jurisdicción no esté enfrentado a normas internacionales sobre inmunidades de la jurisdicción penal de que gozan los jefes de Estado, jefes de gobierno, ministros de asuntos exteriores y agentes diplomáticos" (Cassese, 2007, p. 34). 
Cassese, pese a todo, está de acuerdo en que haya una jurisdicción universal condicionada a la permanencia del inculpado en el territorio del Estado que pretende juzgarlo (2007, p. 35); además, plantea una jurisdicción mixta en la que cada vez que un Estado no pueda o no quiera juzgar se cuente con la presencia de jueces internacionales (Gil, 2005, p. 17). Esto tendría como beneficio que la jurisdicción nacional tiene todas las posibilidades en materia de aportar los medios coercitivos para ser eficaz la justicia, diluyendo algunos de los problemas constantes en este tipo de justicia como es la de convocar a testigos, recolectar pruebas, entre otros aspectos.

Por algunas de las razones expuestas, la Corte Penal Internacional se estableció para brindar una solución a los inconvenientes generados por la impunidad en materia penal, en delitos cometidos por cualquier persona y de conformidad a la magnitud de ciertos crímenes. Se trata de permitir que se haga justicia, cuando se trate de la violación de los derechos humanos o de derechos fundamentales. En otras palabras, en caso de que un país haga una parodia de juicio, y en consecuencia no investigue, no juzgue o no condene, o haga cumplir la condena en situaciones de total, o incluso parcial impunidad, en esos casos, se deberá, acudir a otra tipo de Tribunal que haga justicia. Esto en virtud de que es inaudito que en el mundo actual, existan terrenos jurídicos vedados a la instauración de justicia; del mismo modo que existan medidas alternativas para evadir la acción de la justicia.

\section{EL JUZGAMIENTO DE LA CORTE PENAL INTERNACIONAL DE CRÍMENES DE LESA HUMANIDAD SUCEDIDOS EN COLOMBIA}

En consonancia con lo dicho en el apartado anterior, se puede considerar que algunos delitos que se cometen en Colombia, o que se han cometido, y que no han sido ni tan siquiera investigados, y mucho menos juzgados por los jueces colombianos, alcanzan la naturaleza de delitos de lesa humanidad. Por esta razón serían de competencia de la CPI. Esta apreciación es un tanto optimista, si consideramos, que hasta el momento el accionar de este organismo de justicia supranacional es muy lento. Pero hemos de considerar que en aquellos casos en los que un delincuente incurra en un delito (o varios) y este no haya sido condenado con una pena irrisoria o bien sea absuelto y en consecuencia ese acto criminal haya quedado impune, la justicia internacional, bien sea la Corte Penal Internacional, o muy seguramente alguno de los países europeos que consideran que tienen la capacidad para ejercer a cabalidad la jurisdicción internacional, podrán investigar y juzgar a estos criminales, especialmente si se trata de crímenes de Lesa humanidad; en consecuencia, no importa si hace muchos o pocos años sucedieron los hechos, esto en razón de la imprescriptibilidad de estos crímenes.

Como señala Frulli (Cassese, 2007, p. 337), la imprescriptibilidad de los crímenes de competencia de la CPI, al menos los considerados graves, se están consolidando en la doctrina y los Estados deben adaptar sus legislaciones nacionales para su incorporación ya sean o no parte del estatuto de la CPI. Ese Estatuto reza en el artículo 28 que los crímenes de la competencia de la Corte no prescribirán. En torno a esta vital característica de no prescripción de la acción, es de recordar que fue sólo hasta 1968 en la Convención sobre la Imprescriptibilidad de los Crímenes de Guerra y los Crímenes Contra la Humanidad en el artículo 4 en los que se hizo referencia a la prescripción tanto de la acción pública como de la pena. (Amati, 2009, p. 333).

Es de recordar que fue sólo hasta 1968 en la Convención sobre la Imprescriptibilidad de los Crímenes de Guerra y los Crímenes Contra la Humanidad en el artículo 4 en los que se hizo referencia a la prescripción tanto de la acción pública como de la pena (Frulli, 2009, p. 333).

Ahora bien, en Colombia todos los homicidios, las masacres, las torturas, las violaciones, 
las desapariciones y los desplazamientos forzados, entre otras infracciones a los derechos humanos, son delitos de lesa humanidad según la Corte Suprema de Justicia (Sentencia 32022 del 21 de septiembre de 2009). Esto en razón a que los ataques han sido sistemáticos contra la población civil. Como lo enseñan la historia, la jurisprudencia de los tribunales ad hoc y el Estatuto de la Corte Penal Internacional, todo ataque sistemático, generalizado e inhumano contra la población civil, con el fin de exterminarla por razones políticas, religiosas, raciales o de otra índole, sin importar que se ejecute en tiempos de paz o de guerra, es un crimen de lesa humanidad.

A pesar de que la Constitución colombiana teóricamente le da una importancia mayor a la aplicación de los instrumentos internacionales de derechos humanos en el derecho interno, la verdad es que es una existencia más formal que real. En este caso puede darse tal grado de presión internacional que lleven al restablecimiento de los derechos violados o al resarcimiento de los perjuicios ocasionados a las víctimas; o también obligar al Estado infractor a diseñar un modelo de Estado verdaderamente democrático y respetuoso de los derechos fundamentales.

Hemos de especificar aquí, que el principal problema radica en la criminalización a que hay lugar por parte de un agente del Estado. Bien se sabe que, esa es una "ventaja" con que cuenta el terrorismo de Estado. Desde el punto de vista del sujeto activo, la exigencia en el tipo de ataque contra la población civil viene a representar en estos momentos una actuación de conformidad con políticas de Estado o de una organización no estatal pero que ejerce el poder político "de facto". También la exigencia de ataques masivos o sistemáticos o que se ejerzan en el marco de una política o plan estatal.

Como corolario tenemos que la Comunidad Internacional (cualquier país lo podría hacer, por vía del PJU), puede asumir el compromi- so de perseguir crímenes de lesa humanidad, o eventualmente aplicar el Estatuto de la CPI. En estas dos instancias de justicia, junto a la justicia ordinaria, se puede establecer la responsabilidad penal, del delincuente ejecutor de delitos en contra de la humanidad (Torres Vásquez, 2009, p. 145). Empero, es obligado comentar que en la Corte Interamericana de Derechos Humanos ( $\mathrm{CIDH}$ ) se viene castigando a los Estados que toleran de algún modo la ejecución de delitos de lesa humanidad.

En ese sentido, hay que matizar que es fundamental la responsabilidad internacional del Estado que se ha venido atribuyendo en las sentencias de la Corte, ya sea por acción u omisión al Estado, además sin importar para nada la jerarquía de los participes en el hecho. Para tal fin no hay necesidad de determinar que existió responsabilidad penal de los autores, ni tampoco es necesario identificarlos, tal y como sucede en derecho penal. No, para ejercer su competencia, la Corte, señala que solo es necesario que violen cualquiera de los derechos de la Convención Americana (Así, se ha visto en numerosas sentencias de la $\mathrm{CIDH}$, tal como el caso del Penal Miguel Castro Castro. Sentencia de 25 de noviembre de 2006. Serie C No. 160, párr. 132; caso Masacre de Pueblo Bello, Sentencia de 31 de enero de 2006. Serie C No. 140, párr. 55; caso de la "Masacre de Mapiripán". Sentencia de 15 de septiembre de 2005. Serie C No. 134, párr. 59. Masacre de la "Róchela" contra Colombia, del 11 de noviembre de 2007). En consecuencia: "es suficiente la demostración de que ha habido apoyo o tolerancia del poder público en la infracción de los derechos reconocidos en la Convención, omisiones que hayan permitido la perpetración de esas violaciones o que exista una obligación del Estado que haya sido incumplida por éste" (García, 2000, p. 130).

Aclaremos sí se configuran como crímenes de lesa humanidad, la verdad es que tienen que ser perseguidos en primer lugar por la ley colombiana; ya que, no es una facultad sino una 
"obligación derivada del Derecho Internacional de investigar, perseguir y condenar en su caso, los delitos y crímenes contra la humanidad sin importar en absoluto el ejecutor de los mismos"; siguiendo a García Arán, la cuestión es que tal como se hizo en España se condene a cualquiera que cometa este tipo de crímenes, en aplicación del PJU, bajo está consideración se ha condenado a los criminales de las dictaduras argentina y chilena (2000, p. 34).

En caso de inaplicación del derecho internacional y la premisa señalada, en algunos procesos la competencia recaería en la CPI, bajo el principio de complementariedad. Pero estas acciones criminales, para el caso colombiano, sólo serían posibles para aquellos delitos cometidos con posterioridad al primero de julio de 2002, ya que no existe retroactividad. Igualmente, debemos destacar nuestras serias dudas sobre la aplicación real de justicia por parte de la Corte, además de que en nada compromete la responsabilidad del Estado.

Así pues, es mucho más factible que se aplique justicia a delitos de Lesa humanidad o genocidio sucedidos en Colombia con anterioridad al año 2002, siempre que se subsuma típicamente los hechos en las normas de un Estado que aplique el PJU. De tal modo que pueda asumir la competencia algún tribunal de cualquier país que tenga y pueda aplicar la ley internacional bajo el principio enunciado. Por ese medio, un tribunal penal de cualquier país puede ejercer "su jurisdicción penal respecto de crímenes cometidos en el extranjero contra intereses de la comunidad internacional en su conjunto" (Orihuela, 2005, p. 156). Esta es la llamada justicia supranacional que ha traído beneficios en tanto ha evitado la impunidad para delitos de trascendental importancia para la colectividad internacional. Y que, por supuesto, será útil el PJU en la medida en que asuma como juez natural en las causas que se ventilen por terrorismo de Estado.

Es seguramente imposible prever las consecuencias que traerá consigo el empleo de la extraterritorialidad en cuanto al ejercicio soberano de la justicia en el ámbito interno, lo que es perceptible no será la disminución de Estados que lo practiquen, si no que sus acciones serán cada vez menos violatorias de los derechos humanos, esto es una talanquera para gobiernos corruptos violadores de los derechos humanos, ya que se puede, gracias a la extraterritorialidad de la ley penal, aplicarla a grandes dirigentes gubernamentales o a sus asociados, en general a aquellos individuos usados como instrumentos para cometer crímenes de Estado.

Esta es una clara muestra de aplicación de un derecho penal internacional. Kai Ambos dice que el derecho penal internacional es "el conjunto de todas las normas de derecho internacional que establecen consecuencias jurídicopenales" (2005, p. 13), la evolución de ese Derecho penal internacional, en cuanto a la responsabilidad penal de los individuos que cumplen funciones en el gobierno, se debe en gran parte a todo el proceso que implicó los juicios de Núremberg y Tokio; la estimación jurídica del Tribunal de Núremberg, respecto a la responsabilidad individual de quien detenta la condición de funcionario estatal, más concretamente de quien hace parte de un crimen de derecho internacional, se impone bajo el criterio de que "los crímenes contra el derecho internacional son cometidos por hombres, no por entidades abstractas, y sólo mediante el castigo a los individuos que cometan tales crímenes pueden hacerse cumplir las disposiciones del derecho internacional" (Barberis, 1984, p. 25).

Fierro argumenta, con mucha razón, que "para la mayoría de los crímenes tipificados por las diversas convenciones (terrorismo, trata de personas, tráfico ilícito de armas, delincuencia organizada, tráfico ilícito de estupefacientes, etc.) sigue rigiendo el concepto de principio universal que atribuye jurisdicción a cualquier país que atrape al delincuente (2007, p. 476). Por lo tanto, se puede afirmar que muchos de los crímenes sucedidos en Colombia ejecutados por agentes 
estatales o por particulares que actúen con su beneplácito, aunque actos dispersos, pueden ser considerados crímenes de lesa humanidad.

Lo anterior, debido a que en la jurisprudencia internacional se ha dicho que: "actos diseminados adquieren la connotación de crímenes contra la humanidad cuando se colocan en el contexto de una amplía campaña desencadenada contra la población civil (Amati, 2009, pp. 409-410). Y no se puede excluir en la interpretación de lo que ocurre en Colombia, que los actos criminales diseminados contra la población civil han sido de tal magnitud que ésta ha sido la mayormente afectada, por lo tanto, podemos decir que típicamente se insertan en los llamados delitos de lesa humanidad y que muchos de ellos son acciones en los que la condición para ser tenidos como un terrorismo de Estado son constantes.

Recordemos que en el terrorismo de Estado la finalidad, no es la de subvertir el orden constitucional, sino, en teoría, preservarlo, a pesar de expresar que las medidas coercitivas son para tener cierto grado de paz aceptable, la verdad es que está presente en su accionar alterar gravemente la paz pública y, de ese modo, establecer unas políticas de terror, en contra de los que, supuestamente, han socavado la paz pública. En esa dinámica, ulteriormente lo que se desea es la preservación del sistema a toda costa (Torres, 2010, p. 142).

\section{IMPUNIDAD EN COLOMBIA A TRAVÉS DE LA LEY DE JUSTICIA Y PAZ, POSIBILIDAD DE ACUDIR A INSTANCIAS INTERNACIONALES}

El ejercicio de la acción penal, tratándose, de crímenes internacionales, tiene numerosas dificultades que se tratan de evitar con la creación de normas que procuran reducir las posibilidades de impunidad de estos crímenes. Esta impunidad es mayor en Estados como el colombiano en donde se dice en un discurso estatal, -impregnado de mentira- que se per- manece en riesgo, debido al accionar terrorista de las FARC. Este hecho ocasiona que la mayoría de la sociedad no sea consciente del carácter contradictorio, del tratamiento a ciertos criminales para-políticos y/o paramilitares y a cierto sector de las guerrillas. Amén de la concentración del poder legislativo en manos del ejecutivo, precisamente como una gran incidencia en el órgano judicial, todo esto, significa que se tenga como verdad absoluta el discurso falaz del gobierno. Empero, el Estado colombiano está obligado a cumplir con los requerimientos de la comunidad internacional.

En concordancia con lo dicho, Pizarro consideraba hace varios años, que: "ni los grupos paramilitares ni los grupos guerrilleros van a poder escapar a la justicia nacional o, en su defecto, a la justicia internacional" (2005, p. 2). Eso es lo que esperaban tanto los defensores de derechos humanos lo mismo que la comunidad internacional y, en general, la sociedad colombiana. Sin embargo, con la aplicación de la llamada "Justicia Transicional", y a través del Comité de Reconciliación y Reparación (CRR), el cual tiene como función principal la puesta en marcha de la Ley de Justicia y Paz, se ha tratado de garantizar a las víctimas la verdad, justicia, reparación y garantía de no repetición, no obstante, en el 2013, sin temor a equivocarnos, podemos decir que esa Ley es puro derecho penal simbólico.

Recuérdese que, estas son de usanza preferente en medio de dictaduras, gobiernos totalitarios, o en seudo-democracias. Valga de ejemplo, la Ley de justicia y paz, que en Colombia, tiene una actuación de un indiscutible derecho penal simbólico, "con esta expresión la doctrina se ha referido en los últimos años a aquel tipo de legislación producida de cara a la opinión pública para aparentar una efectividad de la tutela, pero en la conciencia de su real inefectividad" (Hassemer, 1989, p. 173). Ley que fue elaborada, entre otros fines, con el ánimo de llegar a una reconciliación nacional y reconstrucción de la verdad y que hubiese reparación para las víctimas. 
Son tan conscientes de su inefectividad, que, inicialmente, la elaboraron para juzgar paramilitares, pero, en vista de su éxito, la extendieron a miembros de grupos guerrilleros. Esta ley, actualmente, "deambula por el laberinto de la morosidad judicial (...), sin verdad, justicia y reparación, la Ley de Justicia y Paz continúa en un limbo extenuante" (El Tiempo, octubre 4 de 2009); la crítica es absolutamente válida.

Esa ley es de tal calado, que las penas son ínfimas, no guardan ninguna proporción frente a la magnitud de los crímenes cometidos por quienes a ella se acogen, por lo tanto, es una política criminal que ensalza, insisto, el derecho penal simbólico. De esta postura es Díez Ripolles quien afirma "En último término, la política criminal moderna, incapaz de prevenir eficazmente los comportamientos que le preocupan, termina asignando al derecho penal una función meramente educadora, que le hace caer en las redes del derecho penal simbólico" (2005, p. 9).

Cuando se inicia en Colombia la extradición a los EE.UU de personas vinculadas a procesos que hacen parte de la Ley de Justicia y Paz se llega a concluir que se despoja de su competencia a la Corte Penal Internacional, debido a que se aplicaría el principio de complementariedad que rige la justicia penal internacional. No obstante, para Valencia Villa, con quien coincidimos plenamente, en la medida en que la aplicación de la Ley de Justicia y Paz condujera a la "apariencia o simulación de justicia", (Valencia, 2005, p. 8), la CPI. sería competente por genocidio y crímenes contra la humanidad. Es destacable que los responsables de crímenes contra la humanidad no pueden obtener asilo político ni status de refugiados, tampoco es viable que argumenten la exclusión de su responsabilidad penal en virtud de obediencia debida. Junto a esta vital característica se halla la de que no prescribe la acción.

Pizarro, quien dirige el Comité de Reconciliación y Reparación (CRR) entidad encargada de hacer realidad la denominada "justicia res- taurativa", era lapidario en su conclusión en 2006 respecto a la Ley de Justicia y Paz, afirmando que: "no es lo deseable en términos de plena justicia frente al horror de los crímenes perpetrados por los grupos paramilitares y los movimientos guerrilleros. Pero, si constituye un marco básico para lograr el equilibrio entre las exigencias de la justicia y los requerimientos de la paz, es decir, un marco que permite a la vez pensar en las víctimas de ayer e impedir las víctimas de mañana”. No obstante que su visión no era muy alentadora, parece que, a la luz de los resultados de hoy, se quedó corto, en su apreciación.

La Ley de Justicia y Paz no cumple las expectativas de la comunidad nacional e internacional en todo lo que de brindar justicia se trata. Es un despropósito en términos de ser muy garantista con determinados tipos de delitos y de delincuentes. Si los delitos son juzgados de conformidad con el derecho interno, a la luz del ordenamiento jurídico internacional, la discusión se puede centrar en sí efectivamente se aplica justicia. En el mismo sentido, se puede reprochar, si con una mediana exactitud esta ley, hace realmente justicia, o si, por el contrario, es una burla a los postulados internacionales en materia de derechos humanos y de derecho internacional humanitario.

Teniendo en cuenta, que numerosos crímenes sus autores son, en un juicio de adecuación típica y de conformidad al derecho internacional, autores de delitos de Lesa humanidad. Y que en atención a que están siendo castigados por la Ley de Justicia y Paz por la cual obtienen penas irrisorias. Todo esto puede ser considerado como abiertamente inaceptable, de acuerdo a directrices internacionales en materia de hacer que exista una genuina y ecuánime justicia, en la que se cumplan los postulados de verdad, justicia y reparación que teóricamente pretende cumplir con el desarrollo de la Ley de Justicia y Paz.

Lo que se pide es que la puesta en práctica de esa ley, sea de forma real y no alegórica, 
como parece ocurrir. La cuestión aquí adquiere una dimensión importante, si se analiza la posibilidad de "reabrir" algunos casos que, en razón a las nuevas perspectivas internacionales, en las que, eventualmente, algunos, si no todos, los crímenes ya juzgados y con condenas en Colombia, sean considerados delitos de lesa humanidad y se puedan volver a juzgar en tribunales internacionales. En esa dirección se puede señalar que hacen parte de las llamadas sentencias fraudulentas, consideradas así por ser sentencias que propenden por una impunidad disfrazada. Lo que deriva en la posibilidad de iniciar un nuevo proceso penal por los mismos hechos sin violar el principio del derecho penal nom bis in ídem.

Así lo ha determinado la Corte Interamericana de Derechos Humanos, mediante sentencia en el caso Almonacid Arellano y otros Vs Chile, del 26 septiembre de 2006 (Serie C núm. 154). Allí la Corte, ha dicho:

En lo que toca al principio ne bis in ídem, aun cuando es un derecho humano reconocido en el artículo 8.4 de la Convención Americana, no es un derecho absoluto y, por tanto, no resulta aplicable cuando: i) la actuación del tribunal que conoció el caso y decidió sobreseer o absolver al responsable de una violación a los derechos humanos o al derecho internacional obedeció al propósito de sustraer al acusado de su responsabilidad penal; ii) el procedimiento no fue instruido independiente o imparcialmente de conformidad con las debidas garantías procesales, o iii) no hubo la intención real de someter al responsable a la acción de la justicia. Una sentencia pronunciada en las circunstancias indicadas produce una cosa juzgada "aparente" o "fraudulenta". Por otro lado, esta Corte considera que si aparecen nuevos hechos o pruebas que puedan permitir la determinación de los responsables de violaciones a los derechos humanos, y más aún, de los responsables de crímenes de lesa humanidad, pueden ser reabiertas las inves- tigaciones, incluso si existe un sentencia absolutoria en calidad de cosa juzgada, puesto que las exigencias de la justicia, los derechos de las víctimas y la letra y espíritu de la Convención Americana desplaza la protección del ne bis in idem.

El asidero legal y jurisprudencial de esta afirmación se encuentra conforme con la doctrina de la CIDH (26-09-2006), en el sentido de que no se puede dejar de cumplir la imperatividad de la imprescripción que se desprende de un delito al ser calificado de lesa humanidad, en dicha sentencia la Corte dijo:

Aun cuando Chile no ha ratificado dicha Convención, esta Corte considera que la imprescriptibilidad de los crímenes de lesa humanidad surge como categoría de norma de Derecho Internacional General (ius cogens), que no nace con tal Convención sino que está reconocida en ella. Consecuentemente, Chile no puede dejar de cumplir esta norma imperativa.

\section{COLOMBIA Y LA EXTRATERRITO- RIALIDAD DE LA LEY PENAL}

El derecho penal se globaliza en un aspecto que es, -a nuestro modo de ver,- bien importante, la extraterritorialidad de la ley penal, aunque, es muy severo, por ejemplo, con la imposición de penas de cadena perpetua, es preferible a la total ilegalidad de las acciones contra el terrorismo, que ya se ha dicho, llegan a ser terrorismo de Estado. La extraterritorialidad de la ley penal, se quiere imponer de dos maneras, a saber: a través de la Corte Penal Internacional, $\mathrm{y}$, otra, en provecho del PJU. De este último y, sus implicaciones durante la globalización en medio de la sociedad de riesgos actual y la idea de evitar la impunidad, al menos en delitos de lesa humanidad, tema del cual nos ocuparemos en seguida.

En primer lugar: hay que manifestar que la extraterritorialidad significa que un Estado pue- 
de investigar y juzgar crímenes sucedidos en Colombia (o en cualquier parte del mundo) y que esa práctica extensiva, es de naturaleza supranacional. Así mismo, los límites espaciales de aplicación territorial de la ley penal mayoritariamente conocida, tienen límites y requisitos taxativos (subsidiariedad y complementariedad, por ejemplo), que son superados aplicando el PJU. En conclusión, en este momento se brinda justicia en dos tribunales, especialmente, veamos:

Como primera medida, el Estatuto de Roma, en su preámbulo señala que es deber de ellos proceder al ejercicio de la jurisdicción universal: "Recordando que es deber de todo Estado ejercer su jurisdicción penal contra los responsables de crímenes internacionales". La Corte Penal Internacional hace parte de la necesidad de perseguir crímenes internacionales, con el manejo del PJU. Pero, no es el único ni el más efectivo, la justicia universal que se ha venido efectuando en países como España, parece ser más oportuna y eficaz.

En segundo lugar: la responsabilidad se determina por la participación en crímenes internacionales en cualquiera de las formas establecidas en el derecho penal, esto es autor, coautor, determinador, colaborador, cómplice, etcétera. La consideración de crímenes internacionales se regula en Colombia, en la ley 742 de 2002 por medio de la cual se aprobó el Estatuto de la Corte Penal Internacional, hecho en Roma, el día diecisiete (17) de julio de mil novecientos noventa y ocho (1998); en ella se considera que los crímenes más graves de trascendencia para la colectividad internacional en su conjunto no deben quedar sin castigo, no deben quedar impunes.

En consecuencia, hoy todo individuo en ejercicio del PJU, sin contar el lugar en donde se halle $\mathrm{y}$, sin importar en nada aspectos como su raza, color, religión, su nacionalidad o su situación económica es sujeto tanto de derechos de carácter internacional, lo mismo que de obligaciones en materia penal de aplicación de una justicia supranacional. Razón de más, la tienen para preocuparse los perpetradores de crímenes de lesa humanidad, ya que en el contexto señalado cualquier persona puede ser investigada, juzgada, o condenada a penas de prisión muy largas, llegando a ser hasta de cadena perpetúa.

En general, pueden ser sanciones que superan con creces, las penas establecidas en la legislación interna de su país de origen, e incluso puede ser obligado a cumplir esa condena en suelo extranjero. Esta responsabilidad penal internacional es considerada, concretamente, por la violación de los derechos humanos, lo cual es enormemente factible en países que transgreden normas dimanantes de la Declaración Universal de los Derechos Humanos y que hasta ahora han permanecido en la impunidad, casos como los de Cuba, China, EE.UU o Colombia son representativos de tales atrocidades que no han sido por acción o por omisión juzgadas de conformidad con los actuales estándares del derecho internacional.

\section{CONCLUSIONES}

El PJU permite "ejercitar la jurisdicción del Estado más allá del lugar donde se extiende su soberanía y ello tanto sí el delito ha sido cometido por nacionales como por extranjeros" (Lamarca 2001, p. 1100), siempre en persecución de crímenes graves y/o intolerables. El principio es una moderna forma de aplicar justicia y de evitar la impunidad en delitos cometidos por cualquier persona en cualquier parte del mundo siempre que atenten contra bienes jurídicos de características universales. El tradicional concepto de soberanía pierde su esencia en la medida en que los Estados permiten que otros Estados hagan justicia contra sus connacionales. En ese aspecto la globalización política se manifiesta en palabras de Silva, (2001, p. 69) cuando estima "irrelevantes las disposiciones de exención o extinción de responsabilidad penal dictadas por los Estados en cuyo territorio se cometió el delito". 
De este modo, se va eliminando la tradicional idea sobre el concepto de soberanía estatal, y, por ende, se denota la prevalencia del derecho internacional sobre el nacional. En otras palabras, con la aplicación del PJU se permite a los Estados que sus jueces o tribunales tengan la competencia de poder juzgar determinados crímenes internacionales sea cual fuere el lugar en que se hayan cometido sin tener para nada en consideración la nacionalidad de los sujetos activos y/o pasivos. El principal argumento para someter a un individuo a ese tipo de justicia radica en que los crímenes cometidos por este ofenden a la comunidad internacional en su conjunto y su persecución es universal y no se debe fragmentar entre los diferentes Estados.

La crítica que se hace a esa práctica de jurisdicción universal tiene que ver con la exclusión de la sanción penal, cuando en un Estado se impone una pena en clara vulneración de derechos fundamentales, es decir, es difícil que un Estado impida que otro vulnere los derechos humanos; de este modo, señala Silva Sánchez, el derecho penal se expande en lugar de restringirse (Silva, 2001, p. 70). No podemos decir que el PJU sea una medida suficiente, lo que es notorio es el avance que tiene su práctica cuando de evitar la impunidad se trata.

En razón a la posibilidad de que un número cada vez mayor de crímenes lleguen a ser investigados en tribunales internacionales $y$, junto a este significativo número, el que efectivamente se haga justicia de manera ejemplar sirve como mecanismo de disuasión frente a quienes tradicionalmente han cometido cierto tipo de crímenes que han quedado impunes. Ha sido valioso el aporte dado desde el año 2001 en el que se produjo el texto definitivo conocido como los principios de Princeton, en el cual se establecieron algunas directrices para lograr hacer real el PJU.

En esa dirección, el terrorismo sucedido en Colombia, ya sea el efectuado hacia el Estado por los diferentes autores: guerrillas, para- militares y delincuentes comunes, o el llevado a cabo por agentes del Estado, puede ser sometido a cualquier jurisdicción universal en ejercicio del PJU. Del mismo modo, Colombia puede hacer justicia en virtud de ese mismo Principio con los extranjeros que cometan delitos en el extranjero, contra bienes jurídicos del extranjero.

Esta es, pues, una moderna concepción de aplicación de justicia que trae como consecuencia el servir de límite al poder criminal de determinados personas o grupos que se han enraizado en la sociedad colombiana.

\section{REFERENCIAS}

Amati, E. (2009). Los crímenes contra la humanidad. En Amati, E. et. al. Introducción al Derecho Penal Internacional. Bogotá: Universidad Libre.

Ambos, K., Malarino, E. \& Woyschnik, J. (2005). Temas actuales del Derecho Penal Internacional Contribuciones de América Latina, Alemania y España. Montevideo: Editorial Konrad.

Barberis, J. A. (1984). Los sujetos del derecho internacional actual. Madrid: Tecnos.

Casesse, A. \& Delmas, M. (2007). Crímenes internacionales y jurisdicciones internacionales. Bogotá: Norma.

Corte Interamericana de Derechos Humanos. (2005). Sentencia de 15 de septiembre de 2005. Serie C No. 134, párr. 59. Caso Masacre de la "Rochela" contra Colombia.

Corte Interamericana de Derechos Humanos. (2006). Sentencia de 25 de noviembre de 2006. Serie C No. 160, párr. 132. Caso Masacre de Pueblo Bello.

Corte Interamericana de Derechos Humanos. (2006). Sentencia de 31 de enero de 2006. 
Serie C No. 140, párr. 55. Caso de la "Masacre de Mapiripán”.

Corte Interamericana de Derechos Humanos. (2006). Sentencia del 26 septiembre de 2006 (Serie C No. 154). Caso Almonacid Arellano y otros Vs Chile.

Corte Suprema de Justicia. Proceso 16724 de agosto 2 de 2001 (M.P. Dr. Carlos Augusto Gálvez Argote.

Fierro, J. (2007). Ley Penal y derecho internacional. Doctrina y jurisprudencia nacional y extranjera. Buenos Aires: Astrea.

Forer, A. (2010, Septiembre 24). La Corte Penal Internacional: ¿Es una Corte Penal Internacional para África? El Tiempo.

Frulli, M. (2007). El derecho internacional y los obstáculos a la implementación de la responsabilidad penal por crímenes internacionales. En Cassese, A. Crímenes internacionales y jurisdicciones internacionales. Bogotá: Norma.

García, M. (2000). El principio de justicia universal. En García, A. \& López, G. (Eds.). Crimen internacional y jurisdicción universal. El caso Pinochet. Valencia: Tirant lo Blanch. Gil, A. (2005). La sentencia de la Audiencia Nacional en el caso Scilingo. Revista Electrónica de Ciencia Penal y Criminología. 07r1, 17. Disponible en http://criminet.ugr.es/ recpc/07/recpc07-r1.pdf.
Hassemer, C. (1989). Introducción a la Criminología y al Derecho penal. Valencia: Tiran Lo Blanc.

Lamarca, C. (2001). El principio de Justicia Universal y la competencia de la jurisdicción española en los casos de Argentina y Chile. En Arroyo, Luis., \& Berdugo, I. Homenaje al doctor Marino Barbero Santos, in memorian. Salamanca: Universidad Castilla de la Mancha y Universidad de Salamanca.

Orihuela, E. (2005). Crímenes de guerra y justicia universal: avances y retrocesos en la lucha contra la impunidad. En Ramón, C. Derechos $y$ libertades ante las nuevas amenazas a la seguridad global. Valencia: Publicaciones Universidad de Valencia.

Periódico El Tiempo. (2009). Los vacíos de la Ley de Justicia y Paz, octubre 4. Bogotá.

Pizarro, E. (2006). ¿Una ley para la impunidad? Madrid: Fundación Real Instituto Elcano.

Policía Nacional de Colombia. (2009). Los delitos de Terrorismo en el Código Penal Colombiano. Logos Ciencia y Tecnología, Vol. I, 1.

Torres, H. (2010). El concepto de terrorismo de Estado. Una propuesta de Lege de Ferenda. Revista Diálogos de saberes, Universidad Libre, 13, 33.

Valencia, H. (2005). Colombia ante la Corte Penal Internacional. Hechos del Callejón, PNUD, 1, 4. 